\title{
IMPLEMENTASI ALGORITMA IDA* (ITERATIVE DEEPENING A*) DALAM MENENTUKAN SOLUSI TERBAIK PADA PERMAINAN OTHELLO DENGAN SIMULASI MATLAB
}

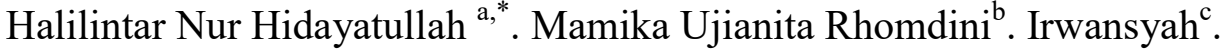 \\ a,b,c Program Studi Matematika FMIPA UNRAM \\ alintar92@gmail.com
}

\section{A B S T R A C T}

Othello is a logical game from Japan. This game played by two players and played on a square board with black and white pawns. Requires high strategy to win this game, that is why this research have two goals. First, to analyz the steps which will be determined using IDA* (Iterative Deepening A*) algorithm, denoted by $f(n)=g(n)+h(n)$ where $g(n)$ is a sum of steps from initial node to node $\mathrm{n}$ with m number of node, and $h(n)$ is estimated distance from node $\mathrm{n}$ to goal node. And second, we found the result of simulation by MATLAB programming.

The simulation program using matrices with size $6 \times 6$ and symbols 1,2, and 0 to represent black pawns, white pawns and empty square. With one of the solution where acquired based on the program are black (9), white (20), black (26), white(10), black (11), white (17), black (23), white (27), black (8), white (6), black (12), white (14), black (33), white (28), black (29), white (31), black (25), white (30), black (7), white (2), black (18), white (13), black (19), white (36), black (35), white(1), black (3), white (34), black (32), white (4), black (5), white (24). And weight $f$-min on each iteration is $14,15,16,17,20,15,16,18,15,16,18,17,13,14,15,16$.

Keywords : IDA* Algorithm, Othello.

\section{Pendahuluan}

Permainan Othello adalah permainan logika asal jepang yang cukup terkenal. Permainan ini dimainkan oleh dua orang, dimainkan pada papan persegi dengan pin putih dan pin hitam. Permainan selesai jika semua kotak telah berisi penuh pin hitam dan putih, atau setiap pemain tidak dapat melakukan pergerakan selanjutnya.

Dibutuhkan strategi dan taktik yang jitu untuk memenangkan permainan ini. Permainan ini dirancang agar manusia dapat melawan Artificial Inteligence (AI).
Algoritma A* (A Bintang) merupakan gabungan dari Algoritma Greedy Best First Search dengan Algoritma Uniform-Cost Search. Algoritma Greedy merupakan algoritma yang cukup optimal dalam mencari sebuah solusi namun terkadang dalam penacariannya tidak didapatkan solusi, sedangkan algoritma Uniform-Cost Search merupakan algoritma yang cukup optimal dan selalu didapatkan solusi dalam setiap pencariannya namun membutuhkan waktu yang cukup lama sehingga kurang efisien.

\footnotetext{
* Corresponding author.lintar92@gmail.com
} 
Algoritma IDA* (Iterative Deepening A Star) merupakan Algoritma $A^{*}$ yang kedalamannya dibatasi pada setiap iterasi pencariannya.Walaupun kompleksitas waktunya lebih tinggi dibanding dengan Algoritma $\mathrm{A}^{*}$, namun Algoritma IDA* tidak membutuhkan memori yang sebesar yang dibutuhkan Algoritma A*.

Matlab merupakan salah satu bahasa pemrograman yang sering digunakan menganalisis teknik komputasi numerik, sehingga akan sangat memudahkan dalam menyelesaikan masalah-masalah yang melibatkan elemen, matriks, optimasi, dll.

Sehingga pada penelitian ini bertujuan untuk menganalisis langkah yang akan ditentukan dalam permainan Othello menggunakan algoritma IDA* dan hasilnya didapatkan berdasarkan simulasi menggunakan pemrograman MATLAB.

\section{Tinjauan Pustaka}

\subsection{Pencarian Heuristik}

Tehnik yang paling efisien dalam menentukan ruang masalah biasanya membutuhkan informasi tambahan berupa sifat-sifat tertentu yang dibangun kedalam setiap keadaan yang terdefinisi [1].

\subsection{Algoritma A*}

Algoritma ini menggabungkan ide antara algoritma greedy best-first search dengan uniform cost search. Biaya yang diperhitungkan didapat dari biaya sebenarnya $g(n)$ ditambah dengan biaya perkiraanh( $n)$. Dalam notasi matematika dituliskan sebagai: $f(n)=g(n)+h(n)$

Dengan perhitungan biaya seperti ini, algoritma $A^{*}$ menjadi komplit dan optimal [13].

\subsection{Algoritma IDA* (Iterative Deepening $A^{*}$ )}

Algoritma IDA* merupakan salah satu variasi dari algoritma $A^{*}$. Sama seperti $A^{*}$, Algoritma IDA* juga komplet dan optimal. Tetapi karena dilakukan secara iteratif, maka IDA* mungkin akan membangkitkan simpulsimpul yang sama secara berulang. Hal ini membutuhkan waktu yang cukup lama. Dengan kata lain kompleksitas waktunya tinggi. Bagaimanapun, keuntungan utama IDA* adalah jumlah memori yang dibutuhkan jauh lebih sedikit [13].

Secara umum algoritma IDA* dapat dilihat pada gambar berikut

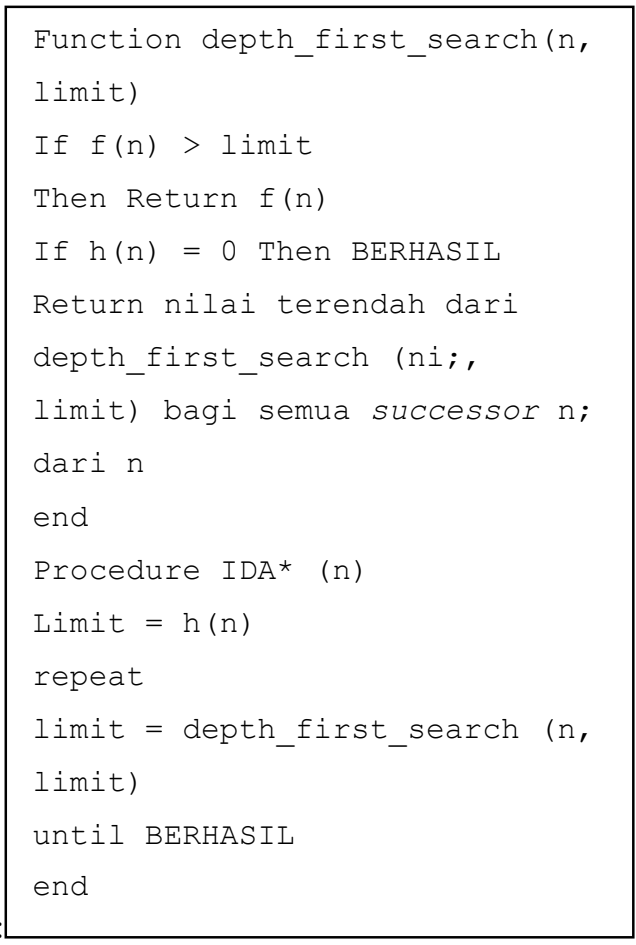

Gambar. 4.1 - Algoritma IDA*

\subsection{Othello (Reversi)}

Permainan Othello adalah permainan logika asal jepang yang cukup terkenal. Dimainkan oleh dua orang pada papan kotak-kotak persegi dengan pin putih dan pin hitam. Permainan ini menuntut strategi yang tinggi sehingga sejak tahun 1977 telah diadakan kejuaraan tingkat dunia hingga saat ini [9].

Permainan diawali dengan meletakkan sepasang keping hitam dan putih ditengah arena, keping hitam pada 
kotak E4 dan D5, dan keping putih pada kotak D4 dan E5 [7]

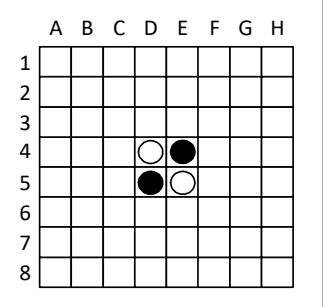

\section{Gambar. 2.7 - Posisi awal permainan Othello $8 \times 8$}

Aturan permainan Othello secara umum adalah sebagai berikut [6] :

a. Setiap pemain memulai permainan dengan masingmasing memiliki 32 koin, salah satu sisi pada setiap koin berwarna hitam dan sisi koin lainnya berwarna putih.

b. Pemain yang menggunakan koin hitam akan bermain terlebih dahulu.

c. Bila pemain koin hitam yang akan bermain, maka koin hitam harus diletakkan di kotak kosong yang berdekatan dengan koin putih. Dan begitu juga kondisinya untuk pemainyang menggunakan koin putih.

d. Pemain harus memainkan langkah dalam posisi 'mengepung' koin lawan. Dengan kondisi bahwa saat pemain melakukan langkah maka koin dengan warna yang berlawanan berada diantara koin dengan warna yang dimainkan pemain. Koin yang 'terkepung' akan berbalik menjadi koin yang sedang dimainkan pemain.

e. Apabila salah satu pemain tidak bermain karena tidak ada kotak yang sesuai dengan aturan (c), maka pemain yang satunya lagi yang bermain.

f. Apabila kedua pemain tidak dapat mengambil langkah lagi, maka permainan berakhir.

Begitupula dengan aturan main Othello ukuran
$6 \times 6$, sehingga posisi awal pada permainan Othello dengan ukuran $6 \times 6$ menjadi sebagai berikut:

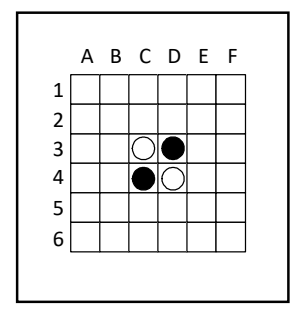

Gambar. 2.8 - Posisi awal permainan Othello $6 \times 6$

\section{Jenis Penelitian dan Sumber Data}

Penelitian ini merupakan penelitian terapan yang dimana menerapkan ilmu tentang kecerdasan buatan untuk memecahkan masalah bagi pemain permainan Othello, agar meminimalisir jumlah langkah dalam memenangkan permainan ini. Serta mengembangkan metode yang pernah digunakan pada penelitian sebelumnya. Dengan data kuantitatif berdasarkan jumlah langkah yang dibutuhkan pemain dalam menyelesaikan permainan.

\section{Hasil dan Pembahasan}

Dalam perhitungannya, algoritma IDA* menggunakan ide yang sama dengan algoritma $\mathrm{A}^{*}$ menggunakan persamaan fungsi $f(n)=g(n)+h(n)$. Dimana $g(n)$ merupakan jarak sebenarnya dari simpul awal menuju suatu simpul $n$. Setiap level pada pohon evaluasi merepresentasikan jumlah langkah ke- $i$ dari posisi awal, sehingga tingkat level pada pohon evaluasi merupakan jarak sebenarnya $g(n)$. Dan $h(n)$ merupakan jarak perkiraan dari simpul $n$ (kotak kosong $n$ yang dipilih) menuju kotak A1 + jarak kotak $n$ menuju kotak A6 + jarak $\operatorname{kotak} n$ menuju kotak F1 + jarak kotak $n$ menuju kotak F6.

\subsection{Perhitungan}

\subsubsection{Perhitungan Iterasi ke-1}


Pada iterasi pertama berdasarkan fungsi IDA* didapatkankemungkinan langkah yang dapat dipilih bidak putih, dengan $f(n)=14$ dan $f(n)=16$. Kemudian dapat dibuat pohon yang merepresentasikan setiap kemungkinan pada langkah 1 untuk bidak putih. Dengan notasi B (titik yang mungkin) untuk bidak hitam.

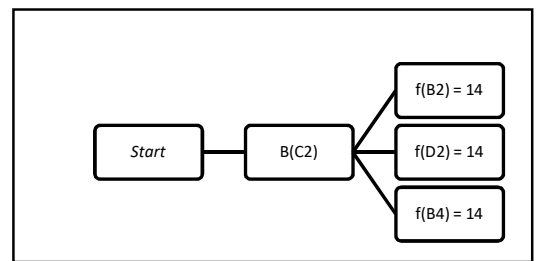

\section{Gambar 4.3 Pohon evaluasi pada iterasi ke-1}

\subsubsection{Perhitungan Iterasi ke-2}

Dari hasil perhitungan iterasi ke-1 kemudian evaluasi langkah yang mungkin dapat dipilih untuk bidak hitam terlebih dahulu yang dilanjutkan perhitungan iterasi ke-2.

Pada iterasi ke-2 berdasarkan fungsi IDA* didapatkan kemungkinan langkah yang dapat dipilih bidak putih, dengan $f(n)=15$ dan $f(n)=17$. Kemudian dapat dibuat pohon yang merepresentasikan setiap kemungkinan pada langkah 2 untuk bidak putih.

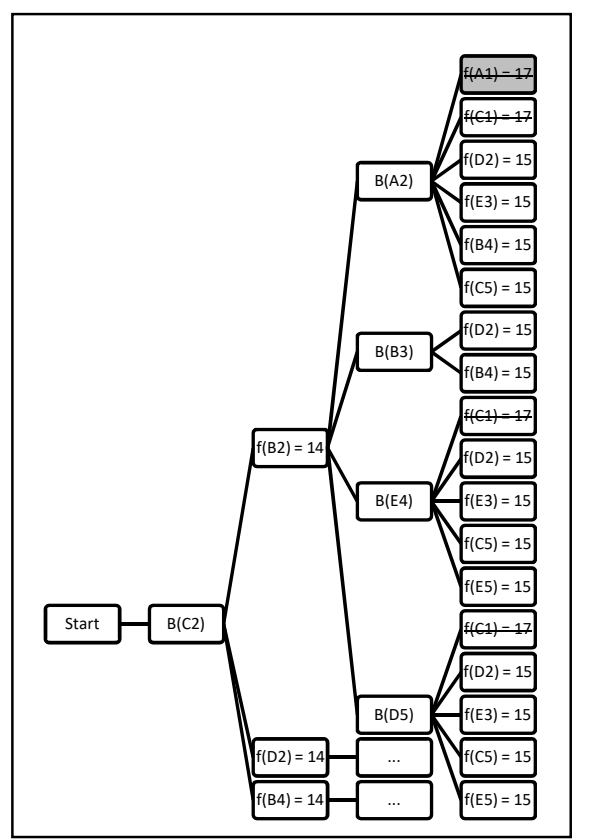

Gambar. 4.4 - pohon evaluasi pada iterasike-2

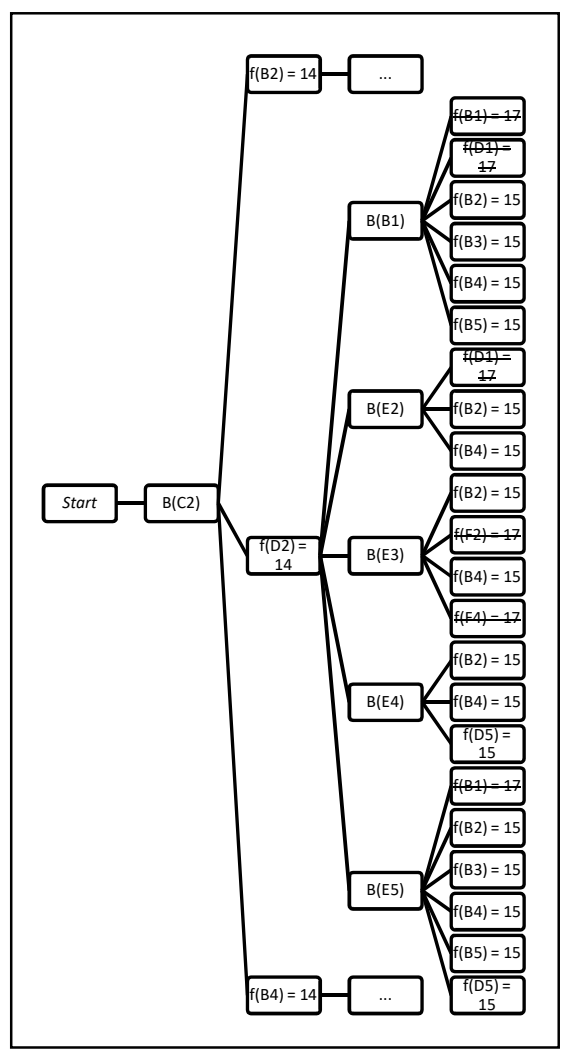

Gambar 4.5 pohon evaluasi pada iterasike-2 


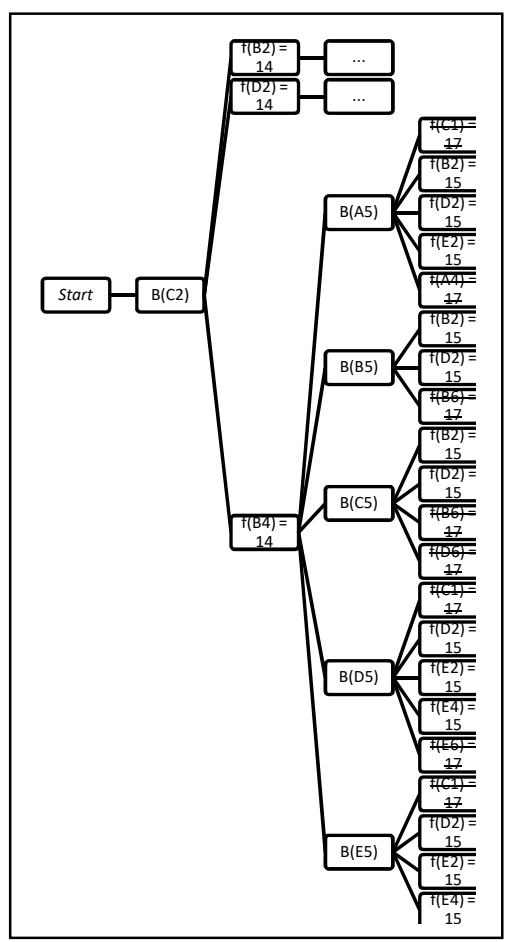

Gambar. 4.6 - pohon evaluasi pada iterasike-2

\subsubsection{Perhitungan Iterasi ke-3}

Dari hasil perhitungan iterasi ke-2 kemudian pilih bobot terkecil lalu evaluasi langkah yang mungkin dapat dipilih untuk bidak hitam terlebih dahulu yang dilanjutkan perhitungan iterasi ke-3.

Pada iterasi ke-3 berdasarkan fungsi IDA* didapatkan kemungkinan langkah yang dapat dipilih bidak putih, dengan $f(n)=16$ dan $f(n)=18$. Kemudian dapat dibuat pohon yang merepresentasikan setiap kemungkinan pada langkah 3 untuk bidak putih.

Karena pada kasus ini tidak banyak variasi nilai $f$ yang dihasilkan pada tiap iterasinya, sehingga nilai $f$-max pada iterasi sebelumnya bisa saja dibangkitkan untuk selanjutnya dianalisis pada pohon evaluasi. Hal ini menyebabkan akan sangat membutuhkan waktu yang cukup lama untuk mengevaluasi semua kemungkinan langkah yang mungkin dapat dipilih.
Oleh karena itu akan dilanjutkan dengan bahasa pemrograman MATLAB sebagai simulasi, dan untuk mempermudah dalam mengevaluasi kemungkinan langkah berdasarkan algoritma IDA*.

\subsubsection{Implementasi Pada Pemrograman MATLAB}

Pada program simulasi ini digunakan matriks ukuran $6 \times 6$ dengan simbol 1 yang merepresentasikan bidak hitam, simbol 2 untuk merepresentasikan bidak putih, dan simbol 0 untuk merepresentasikan kotak yang masih kosong atau belum berisi bidak.

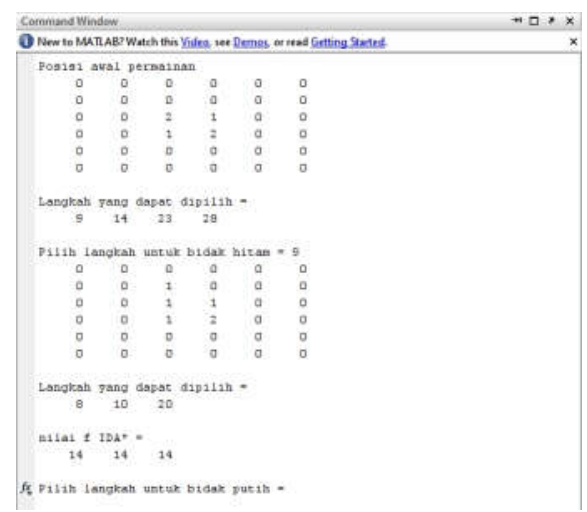

Gambar 4.6 tampilan simulasi dengan pemrograman MATLAB

Gambar diatas menunjukan tampilan simulasi permainan othello berdasarkan algoritma IDA*, dengan salah satu solusi yang didapat pada program dapat dilihat pada tabel berikut:

Tabel 4.1 Salah satu solusi yang didapat dari program simulasi pada bahasa pemrograman MATLAB.

\begin{tabular}{ccc}
\hline Hitam & Putih & Bobot $(\boldsymbol{f})$ \\
\hline 9 & 20 & 14 \\
26 & 10 & 15
\end{tabular}




\begin{tabular}{ccc}
\hline 11 & 17 & 16 \\
23 & 27 & 17 \\
8 & 6 & 20 \\
12 & 14 & 15 \\
33 & 28 & 16 \\
29 & 31 & 18 \\
25 & 30 & 15 \\
7 & 2 & 16 \\
18 & 13 & 18 \\
19 & 36 & 17 \\
35 & 1 & 13 \\
3 & 34 & 14 \\
32 & 4 & 15 \\
5 & 24 & 16 \\
\hline
\end{tabular}

Berdasarkan batasan masalah penelitian ini hanya dicari langkah bidak putih hingga menempati tiap sudut (posisi $(1,1),(1,6),(6,1)$, dan $(6,6))$, hal itu terpenuhi dengan nilai $f=13$, sehingga jika permainan tetap dilanjutkan secara acak tidak akan mempengaruhi hasil permainan dimana bidak putih memenangkan permainan.

\section{Kesimpulan}

Berdasarkan tujuan yang ingin diperoleh serta hasil analisis, maka dapat disimpulkan hal-hal berikut:

1. Berdasarkan fungsi Algoritma IDA* dapat dipilih $f$ min dalam menentukan langkah terbaik untuk memenangkan permainan Othello dengan perhitunga sebagai berikut : $f(n)=g(n)+h(n)$. Dengan $g(n)$ merupakan jumlah langkah dari simpul awal menuju suatu simpul $\mathrm{n}$ dengan $\mathrm{m}$ jumlah simpul (dalam kasus ini sama dengan jumlah level pada pohon evaluasi), $h(n)$ merupakan jumlah jarak dari simpul $\mathrm{n}$ (kotak kosong yang dipilih) menuju kotak $1+$ jarak kotak n menuju kotak $6+$ jarak kotak n menuju kotak $31+$ jarak kotak $n$ menuju kotak 36, dengan syarat kotak 1, 6, 31 dan kotak 36 merupakan kotak kosong, jika salah satu kotak tidak kosong maka jaraknya dengan kotak yang tidak kosong itu sama dengan nol (0). Yang kemudian dianalisis pohon evaluasinya untuk dipilih nilai terkecil dari tiap iterasi berdasarkan algoritma IDA*, didapatkan salah satu pilihan langkah terbaik hingga iterasi 3 yaitu : hitam (9), putih (20), hitam (26), putih (10), hitam (11), putih (17).

2. Pada program simulasi ini digunakan matriks ukuran $6 \times 6$ dengan simbol 1 yang merepresentasikan bidak hitam, simbol 2 untuk merepresentasikan bidak putih, dan simbol 0 untuk merepresentasikan kotak yang masih kosong atau belum berisi bidak. Dengan salah satu solusi yang didapatkan dari program simulasi tersebut adalah : hitam (9), putih (20), hitam (26), putih (10), hitam (11), putih (17), hitam (23), putih (27), hitam (8), putih (6), hitam (12), putih (14), hitam (33), putih (28), hitam (29), putih (31), hitam (25), putih (30), hitam (7), putih (2), hitam (18), putih (13), hitam (19), putih (36), hitam (35), putih (1), hitam (3), putih (34), hitam (32), putih (4), hitam (5), putih (24). Dengan bobot $f$-min pada tiap iterasi 14,15 , $16,17,20,15,16,18,15,16,18,17,13,14,15,16$

\section{DAFTAR PUSTAKA}

[1]. Barr, Avron \& Edward A. Feigenbaum. (1981). The Handbook Of Artificial Intelegence. Vol $1^{\text {st }}$. William Kaufmann Inc : California.

[2]. Botea, Adi, Bruno Bouzy, Michael Buro, Christian Bauckhage. (2013). Pathfinding in Games. Jurnal of Artificial and Computational Intelligence in Games. 
Volume 6. pp. 21-31.

[4]. Budiharto, Widodo \& Derwin Suhartono. (2014). Artificial Intelligence Konsep dan Penerapannya. Penerbit ANDI : Yogyakarta.

[5]. Congdon, Claire Bates, Philip Hingston, \& Graham Kendall. (2013). Artificial and Computational Intelligence for Games on Mobile Platforms. Jurnal of Artificial and Computational Intelligence in Games. Volume 6. pp. 101-108.

[6]. Handayani, Mauza Saputri, Dedy Arisandi, Opim Salim Sitompul. (2012). Rancangan Permainan Othello Berbasis Android Menggunakan Algoritma Depth-First Search. Jurnal Dunia Teknologi Informatika. Vol. 1. No. 1. pp. 28-34.

[7] Lazard, Emmanuel. Othello (r) : The Rules Of The Game. http://radagast.se/othello/Help/strategy.html diakses 8 Mei 2016.

[8] Munir, Rinaldi. (2011). Algoritma \& Pemrograman dalam Bahasa Pascal dan C. Informatika : Bandung.

[9] Prasetyono, Dwi Sunar. (2015). Buku Tutorial Game-Game Kecerdasan. DIVA Press : Yogyakarta.

[10] Pusadan, Mohammad Yazdi. (2014). Pemrograman MATLAB pada system pakar fuzzy. Deepublish : Yogyakarta.

[11] Russell, Stuart J. \& Peter Norvig. (1995). Artificial Intelegence A Modern Approach. A Simon \& Schuster Company : New Jersey.

[12] Sarcone, Gianni A. \& Marie - Jo Waeber. Othello history. 